\title{
ANÁLISE DINÂMICO-MECÂNICA: APLICAÇÕES EM FILMES COMESTÍVEIS
}

\author{
Oscar Mendieta-Taboada* \\ Departamento de Ingeniería Agroindustrial, Facultad de Ingeniería Agroindustrial, Universidad Nacional de San Martín, \\ Jr. Amorarca s/n, Tarapoto - Perú \\ Rosemary A. de Carvalho e Paulo José do A. Sobral \\ Departamento de Engenharia de Alimentos, Faculdade de Zootecnia e Engenharia de Alimentos, Universidade de São Paulo, \\ Av. Duque de Caxias Norte, 225, 13635-900 Pirassununga - SP, Brasil \\ Recebido em 29/1/07; aceito em 14/6/07; publicado na web em 26/2/08

\begin{abstract}
DYNAMIC-MECHANICAL ANALYSIS: APPLICATIONS IN EDIBLE FILM TECHNOLOGY. Edible films are thin materials based on biopolymers and food additives. The aim of this work is a review on the application of dynamic mechanical analysis in edible film technology. After a brief review of the linear visco-elasticity theory, a description of some practical aspects related to dynamic mechanical analysis, such as sample fixation and sample dehydration during analysis and types and modes of tests are presented. Thus, the use of temperature scanning analysis for glass transition and for plasticizer-biopolymer compatibility studies and frequency scanning tests, less common in edible film technology, are critically reviewed.
\end{abstract}

Keywords: biopolymers; glass transition; master curve.

\section{INTRODUÇÃO}

Filmes comestíveis são utilizados há muito tempo para proteger produtos alimentícios perecíveis da deterioração e da perda de qualidade ${ }^{1}$. Nas últimas duas décadas, a quantidade de pesquisas com enfoque no desenvolvimento e caracterização de materiais biodegradáveis e, particularmente, filmes comestíveis, têm aumentado substancialmente, devido às questões de impacto ambiental envolvendo as embalagens sintéticas ${ }^{2}$. Um outro argumento que justifica esse incremento nas pesquisas é o uso de polímeros de fontes renováveis ${ }^{3}$.

Segundo Gontard e Guilbert ${ }^{4}$, a utilização de biopolímeros, isto é, polímeros de origem biológica, na produção de embalagens biodegradáveis, pode ser feita de três maneiras: através de mistura de biopolímeros com polímeros sintéticos, o que provoca um aumento da biofragmentação da embalagem e, conseqüentemente, seu desaparecimento da natureza; uso de produtos ou subprodutos agropecuários como substratos na produção de biopolímeros via fermentação (ex. produção de PHB) e, o uso de biopolímeros diretamente na produção de filmes. Neste último caso se encontram os filmes comestíveis. Portanto, filmes comestíveis são materiais finos e flexíveis elaborados com macromoléculas biológicas capazes de formar uma matriz contínua, contendo aditivos de grau alimentício.

Vários tipos de filmes comestíveis têm sido desenvolvidos, em escala de laboratório, utilizando-se polissacarídeos ${ }^{5}$ e proteínas ${ }^{6,7}$ como biopolímeros. De maneira geral, esses filmes têm sido caracterizados para estudo das suas propriedades funcionais e/ou físicas, com destaque para as propriedades mecânicas, propriedades de barreira (vapor de água, $\mathrm{O}_{2}, \mathrm{CO}_{2}$ e etileno), solubilidade em água, cor, opacidade, entre outras. Um número considerável de trabalhos de revisão sobre propriedades físicas e/ou funcionais de filmes comestíveis encontra-se disponível na literatura especializada ${ }^{8-13}$.

De maneira geral, o comportamento das principais propriedades desses filmes comestíveis tem sido explicado, por exemplo,

*e-mail: oscar_men_98@yahoo.com em termos micro-estruturais, de composição da sua matéria seca e da transição vítrea do materia ${ }^{14}$. Nesse particular, sabe-se que a compatibilidade dos componentes é de grande importância para a característica dos filmes, pois pode afetar de maneira drástica as propriedades dos filmes obtidos.

Muitos equipamentos e métodos físico-químicos têm sido empregados nesses estudos, dentre os quais se pode destacar a análise dinâmico-mecânica (DMA), também denominada análise térmica dinâmico-mecânica (DMTA), usada para relacionar as propriedades macroscópicas, tais como as propriedades mecânicas, as relaxações moleculares associadas a mudanças conformacionais e a deformações microscópicas geradas a partir de rearranjos moleculares da estrutura dos materiais, normalmente associadas às propriedades visco-elásticas do material, permitindo inclusive, a determinação da temperatura de transição vítrea, em virtude de alguma alteração mais drástica na evolução das propriedades visco-elásticas em função da temperatura. Mais detalhes sobre essa determinação serão discutidos no item "varredura de temperatura".

Considerando-se o destaque e a importância do tema filmes comestíveis nos últimos anos e, sobretudo, que não se encontram revisões sobre aplicações da análise dinâmico-mecânica em estudos com esse tipo de biomaterial, o objetivo deste trabalho foi fazer uma revisão sobre o emprego da análise dinâmico-mecânica na tecnologia de filmes comestíveis, com ênfase em estudos cujos autores empregaram varreduras de freqüência e varredura de temperatura.

\section{VISCO-ELASTICIDADE LINEAR}

\section{Fundamentos sobre a teoria da visco-elasticidade linear}

Praticamente, existem dois tipos de testes para se determinar as propriedades visco-elásticas de materiais: estáticos e dinâmi$\cos ^{15-17}$. Nos testes estáticos, uma deformação, ou uma tensão, é imposta e mantida constante durante o teste, sendo que a variação da tensão, ou da deformação, é observada, respectivamente, como resposta durante a evolução do tempo. O primeiro teste é chamado relaxamento de tensão, e o segundo, de teste de fluência. Nesses 
casos, o modelo utilizado no tratamento dos dados estabelece as propriedades visco-elásticas, que podem ser: módulo de elasticidade e módulo de viscosidade, nos testes de relaxamento de tensão, ou módulo de fluência, no segundo teste ${ }^{18}$. Mais detalhes sobre essas propriedades podem ser encontrados na literatura especializada $^{15-17}$.

Nos testes dinâmicos, por sua vez, uma variação senoidal da deformação, ou da tensão, é imposta ao material, e uma variação da tensão necessária à imposição da deformação, ou no segundo caso, a deformação conseqüente da tensão aplicada, é observada como resposta. Em ambos os casos, a tensão e a deformação devem oscilar de acordo com uma curva do seno, entretanto, com um deslocamento da fase entre 0 e $\pi / 2$. Se o material for puramente elástico (Hookeano), o deslocamento da fase será 0 , mas se esse for líquido (Newtoniano), o deslocamento será de $\pi / 2^{16,17}$. Dentre as propriedades visco-elásticas determinadas nestes testes, estão o módulo de armazenamento (G'), o módulo de perda (G') e o ângulo de fase, normalmente calculado como $\tan \delta$.

Normalmente, os modelos usados nesses testes são baseados na teoria da visco-elasticidade linear ${ }^{16}$. Do ponto de vista prático, a visco-elasticidade linear é observada apenas quando a deformação é suficientemente pequena, de modo que as moléculas do polímero sejam "perturbadas" de maneira reversível. Nessa situação, os módulos de tensão de relaxamento, $\mathrm{E}\left(\mathrm{t}, \varepsilon_{\mathrm{o}}\right)=\sigma_{\mathrm{E}}(\mathrm{t}) / \varepsilon_{\mathrm{o}}$, e de cisalhamento, $\mathrm{G}\left(\mathrm{t}, \gamma_{\mathrm{o}}\right)=\sigma(\mathrm{t}) / \gamma_{\mathrm{o}}$, são independentes da tensão ou deformação aplicada ${ }^{19}$.

\section{Propriedades visco-elásticas: medidas dinâmicas}

Quando um material visco-elástico linear é submetido a uma deformação de forma $(\varepsilon)$, oscilando de acordo com a Equação 1:

$\varepsilon=\varepsilon_{\mathrm{o}} \cos (\omega \mathrm{t})$

onde $\varepsilon_{\mathrm{o}}$ é a amplitude máxima da tensão, $\omega$ é a freqüência e t é o tempo; a resposta será a tensão, que também variará (Equação 2), porém defasada da deformação, com um certo ângulo $\delta$, como indicado na Figura 1.

$$
\sigma=\sigma_{\mathrm{o}} \cos (\omega \mathrm{t}+\delta)
$$

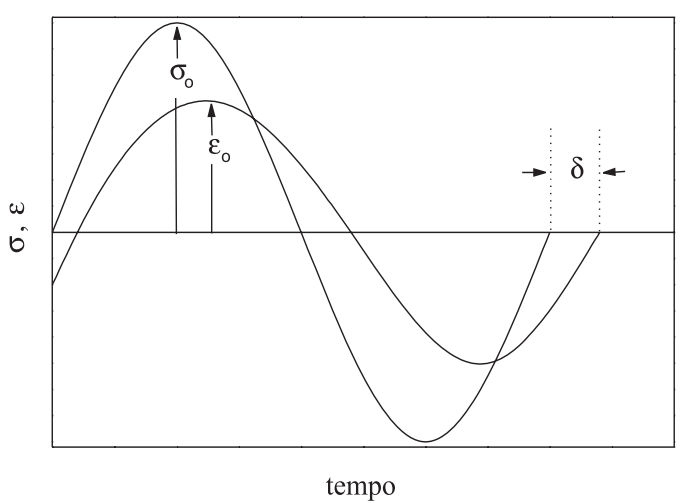

Figura 1. Variação da tensão e da deformação com o tempo em amostra submetida a um sinal oscilatório

A Equação 2 pode ser desenvolvida, obtendo-se:

$\sigma=\sigma_{\mathrm{o}} \cos \delta \cos (\omega \mathrm{t})-\sigma_{\mathrm{o}} \operatorname{sen} \delta \operatorname{sen}(\omega \mathrm{t})$

Com esta última equação, pode-se demonstrar que a tensão pode ser resolvida em duas componentes: $\sigma_{\mathrm{o}} \cos \delta$, que é a componente em fase com a deformação e está relacionada com a energia elástica armazenada (resposta do sólido), e $\sigma_{\mathrm{o}}$ sen $\delta$, que é a componente defasada $90^{\circ} \mathrm{com}$ a deformação e está relacionada com a energia viscosa dissipada (resposta do líquido).

A Equação 3 pode ser ainda rearranjada na forma da Equação 4 definindo-se, assim, as propriedades visco-elásticas, módulo de armazenamento (G') e módulo de perda (G”).

$\sigma=\varepsilon_{\mathrm{o}} \mathrm{G}^{\prime} \cos (\omega \mathrm{t})-\varepsilon_{\mathrm{o}} \mathrm{G}^{\prime} \operatorname{sen}(\omega \mathrm{t})$

Comparando-se as Equações 3 e 4, pode-se observar que os módulos estão dados por:

$\mathrm{G}^{\prime}=\frac{\sigma_{\mathrm{o}}}{\varepsilon_{\mathrm{o}}} \cos \delta \quad \mathrm{G}^{\prime \prime}=\frac{\sigma_{\mathrm{o}}}{\varepsilon_{\mathrm{o}}} \operatorname{sen} \delta$

O módulo de armazenamento representa a energia mecânica armazenada no sistema (porque a resposta do sólido é elástica) por ciclo, enquanto que o módulo de perda representa a energia dissipada por ciclo, que pode ser atribuída ao movimento de longos segmentos da cadeia principal, ou a relaxações de segmentos laterais resultantes, por exemplo, de rotações em torno de ligações.

Uma outra propriedade, o ângulo de fase, também conhecida como tan $\delta$, fator de perda, fricção interna, ou amortecimento, pode ser calculado como a razão entre os valores de G" e de G' (Equação 6). $\mathrm{O}$ ângulo de fase expressa a capacidade de um material em converter energia mecânica em calor, e é considerado muito útil na caracterização de sistemas poliméricos ${ }^{20,21}$.

$\tan \delta=\frac{\mathrm{G}^{\prime \prime}}{\mathrm{G}^{\prime}}$

A propriedade visco-elástica de biomateriais também pode ser representada na forma complexa, conforme Equação 7:

$\mathrm{G}^{*}(\omega)=\mathrm{G}^{\prime}(\omega)+\mathrm{iG} \mathrm{G}^{\prime}(\omega)$

onde $G^{*}$ representa o módulo complexo a uma freqüência $\omega$ e i representa a componente imaginária do número complexo.

Inúmeras outras propriedades visco-elásticas podem ser calculadas a partir de G', G', conhecendo-se a frequiência $(\omega)$ com a qual essas propriedades foram determinadas. Essas propriedades podem ser facilmente encontradas em obras clássicas sobre a visco-elasticidade ${ }^{15-17}$.

As propriedades visco-elásticas são determinadas com equipamentos específicos. No caso de sistemas diluídos, como líquidos visco-elásticos, essas propriedades são determinadas com o auxílio de reômetros, que permitem tanto o controle da tensão, quanto da deformação aplicadas. Vários trabalhos sobre visco-elasticidade de dispersões de biopolímeros ${ }^{22-24}$ e de géi ${ }^{25-35}$ podem ser encontrados na literatura.

Quando o material é sólido e, mais particularmente, quando se trata de filmes flexíveis, o equipamento mais usual para se determinar as propriedades visco-elásticas é o analisador dinâmicomecânico.

\section{ANÁLISE DINÂMICO-MECÂNICA}

A operação e o funcionamento do analisador dinâmico-mecânico (DMA) são relativamente simples de compreender e estão descritos com detalhes em diversos trabalhos ${ }^{20,21,36}$. Uma das aplicações mais comuns da técnica de DMA é na determinação da temperatura de transição vítrea $\left(\mathrm{T}_{\mathrm{g}}\right)$ de materiais permitindo, ain- 
da, a determinação de transições secundárias, que estão relacionadas à relaxação de grupos, ou parte de grupos, laterais da cadeia polimérica e, também, da temperatura de fusão de cristais (Tm) de polímeros parcialmente cristalinos ${ }^{21}$.

O principal inconveniente na utilização do DMA está relacionado com a fixação da amostra na célula de medida e com a interpretação dos resultados. A fixação da amostra na célula de medida do equipamento, assim como as condições experimentais a serem utilizadas, deve ser criteriosa para se obter resultados confiáveis e repetitivos. Além disso, os biopolímeros e alguns biomateriais são produzidos utilizando-se água como solvente, sendo, portanto, muito sensíveis às condições ambientais, notadamente, temperatura e umidade relativa. Considerando-se que a amostra não é protegida por uma cápsula, por exemplo, e que o ambiente na célula de medida é extremamente seco devido ao aquecimento e ao fluxo de gases isento de umidade (nitrogênio e/ou ar), a amostra pode sofrer desidratação, afetando de maneira importante os resultados, uma vez que a água tem um forte efeito plastificante nesses materiais $^{37-39}$. Por causa disso, alguns autores preconizam o uso de graxa de silicone aplicada na superfície da amostra, para proteger o material da desidratação $0^{40-44}$.

Por outro lado, a interpretação dos resultados pode ser difícil em algumas situações, como por exemplo, no caso de sistemas multicomponentes, onde nem sempre é óbvio se confirmar se o fenômeno observado é uma transição vítrea da cadeia principal, uma transição do grupo lateral ou um evento térmico associado com as regiões cristalinas da amostra, entre outras possibilidades ${ }^{45}$, sendo necessárias análises complementares.

\section{Tipos e modos dos testes}

As propriedades visco-elásticas de materiais poliméricos podem ser determinadas por diferentes testes. As diferenças entre esses testes estão justamente nos modos de aplicação da tensão (ou deformação) na amostra, que depende fundamentalmente do sistema de fixação da amostra. A escolha do modo mais adequado deve se respaldar, primeiramente, na tentativa de se reproduzir em laboratório a mesma forma de solicitação presente na situação real. Em alguns casos, devido à dificuldade de se produzir corpos de prova com a forma e o tamanho apropriados para o ensaio, pode-se alterar o modo de solicitação. Considerando-se que essas alterações podem afetar as propriedades visco-elásticas, elas devem ser sempre indicadas com os resultados ${ }^{21}$.

No caso particular de filmes comestíveis, os modos de solicitação mais usados em DMA são: cantilever simples, flexão dupla, flexão em três pontos e tração uniaxial. Normalmente, na aplicação dos modos de cantilever simples, flexão dupla e flexão em três pontos, têm-se trabalhado com filmes comestíveis com espessuras de 1 a $2 \mathrm{~mm}^{2,46-48}$, enquanto que no caso da tração, pode-se trabalhar com espessuras inferiores, menores que $0,4 \mathrm{~mm}^{41,43,49-55}$ (Figura 2).

No caso dos testes de Tração uniaxial, as amostras sofrem uma deformação volumétrica, isto é, as dimensões laterais da amostra sofrem alterações. Como nem sempre é possível se medir essas variações, é praticamente impossível proceder às devidas alterações nos cálculos dos módulos de armazenamento e de perda. Por essa razão, diversos autores representam esses módulos como E' e E”, respectivamente $\mathrm{A}^{41,42,56,57}$. Mudanças análogas ocorrem nas amostras no caso dos testes cantilever simples ${ }^{47,48,58,59}$, flexão dupla ${ }^{60} \mathrm{e}$ flexão três pontos ${ }^{61,62}$.

Na realização de análises com DMA, alguns parâmetros devem ser levados em consideração, como temperatura, freqüência e amplitude máxima da deformação (ou da tensão). Normalmente,

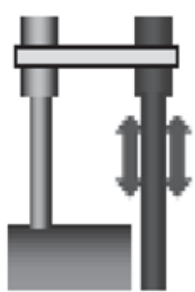

(a)

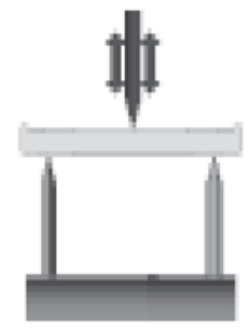

(c)

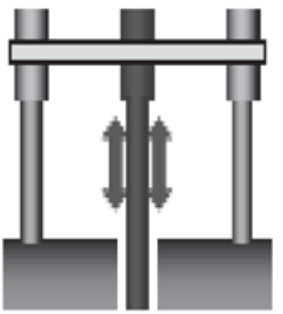

(b)

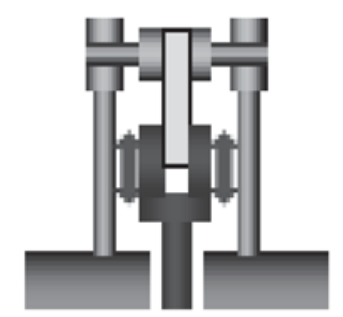

(d)
Figura 2. Tipo de solicitações mais usuais em testes de filmes com DMA: (a) Cantilever simples, (b) Flexão dupla, (c) Flexão três pontos, (d) Tração uniaxial

dois desses parâmetros são mantidos fixos, enquanto que o terceiro pode ser variado em uma determinada faixa, de acordo com o interesse do estudo. Os principais testes são realizados com varredura de temperatura, o que permite determinar as temperaturas nas quais ocorrem alguns fenômenos de relaxação associados a alterações drásticas nas propriedades visco-elásticas; ou com varredura de frequiência, podendo-se obter o espectro de relaxação do material, a partir do qual se determinam todas as funções visco-elásticas, sem a necessidade de experimentos adicionais ${ }^{63}$.

Em ambos os casos, é aconselhável, inicialmente, um estudo para a escolha da amplitude da deformação (ou da tensão). Um valor muito baixo da deformação, por exemplo, pode tornar difícil a quantificação da resposta da amostra, aumentando muito a relação ruído/sinal. Por outro lado, uma grande deformação pode provocar deslocamento na amostra que ultrapasse sua região de viscoelasticidade linear, deformando-a plasticamente, o que deve ser obrigatoriamente evitado ${ }^{21}$.

\section{Varredura de temperatura}

Segundo Canevarolo ${ }^{21}$, para se conhecer as características termo-dinâmico-mecânicas de uma amostra, é necessário varrer uma faixa de temperatura na qual se espera encontrar um fenômeno. Normalmente, na tecnologia de filmes comestíveis, o fenômeno de interesse é a transição vítrea. A fusão de cristais em filmes comestíveis nem sempre é possível de ser estudada com DMA, por causa de rompimento do material na faixa de temperatura onde ocorreria essa transição.

Geralmente, a desidratação de biopolímeros produz material quebradiç $0^{52,64}$. O emprego de agentes plastificantes é necessário para se evitar o caráter quebradiço do filme comestível. Além disso, esse componente, normalmente um poliol, reduz a temperatura de transição de vítrea $\left(\mathrm{T}_{\mathrm{g}}\right)$ do sistema. Em temperaturas abaixo da $\mathrm{T}_{\mathrm{g}}$, o filme se comportará como um vidro frágil, mas em temperaturas acima de $\mathrm{T}_{\mathrm{g}}$, o material existirá em um estado borrachento, 
mais macio ${ }^{65,66}$. As propriedades físicas de filmes são fortemente dependentes da sua temperatura de transição vítrea e, por isso, esse fenômeno tem despertado muito interesse na tecnologia de filmes comestíveis (Tabela 1).

Como no caso das curvas de $\operatorname{DSC}^{37-39}$ (calorimetria diferencial de varredura), também é possível se determinar o valor da $\mathrm{T}_{\mathrm{g}}$ nas curvas de DMA. Normalmente, a transição vítrea é associada a uma inflexão na curva do módulo de armazenamento e/ou a um pico na curva de $\tan \delta$ (Figura 3). Na prática, segundo Cuq et al ${ }^{42}$, a $\mathrm{T}_{\mathrm{g}}$ pode ser calculada como sendo a temperatura onde se inicia a inflexão em E', normalmente chamada de temperatura de "onset" $\left(\mathrm{T}_{1}\right)$; como o ponto onde ocorre a inflexão em E', conhecida como "mid-point" $\left(\mathrm{T}_{2}\right)$; e mesmo como a temperatura onde termina essa inflexão, ou seja, o "end-point" $\left(\mathrm{T}_{3}\right)$, podendo também ser calculada como a temperatura onde ocorre o pico de $\tan \delta\left(\mathrm{T}_{4}\right)$ ou o pico na curva do módulo de perda $\left(\mathrm{T}_{5}\right)$. A temperatura de transição vítrea $\left(\mathrm{T}_{\mathrm{g}}\right)$ pode ser calculada ainda como sendo a temperatura de início da inflexão da curva do comprimento da amostra $\left(\mathrm{T}_{6}\right)$ ou seu ponto de inflexão $\left(\mathrm{T}_{7}\right)$. Mas, segundo Champion et al. ${ }^{67}$, fisicamente, a temperatura da transição vítrea seria a $\mathrm{T}_{4}$ (Figura 3). Por outro lado, vários autores, especialistas em tecnologia de filmes comestíveis, preferem calcular $\mathrm{T}_{\mathrm{g}}$ como sendo uma média entre $\mathrm{T}_{2}$ e $\mathrm{T}_{4}$ (Figura 3 ), além de considerarem que a diferença entre essas temperaturas dá uma medida da amplidão da região de transição vítrea ${ }^{41,58,59,68-70}$. Polêmicas a parte, na maioria dos trabalhos sobre filmes comestíveis, os autores calculam $\mathrm{T}_{\mathrm{g}}$ como o valor da temperatura onde ocorre o pico da curva da $\tan \delta$ (Tabela 1).

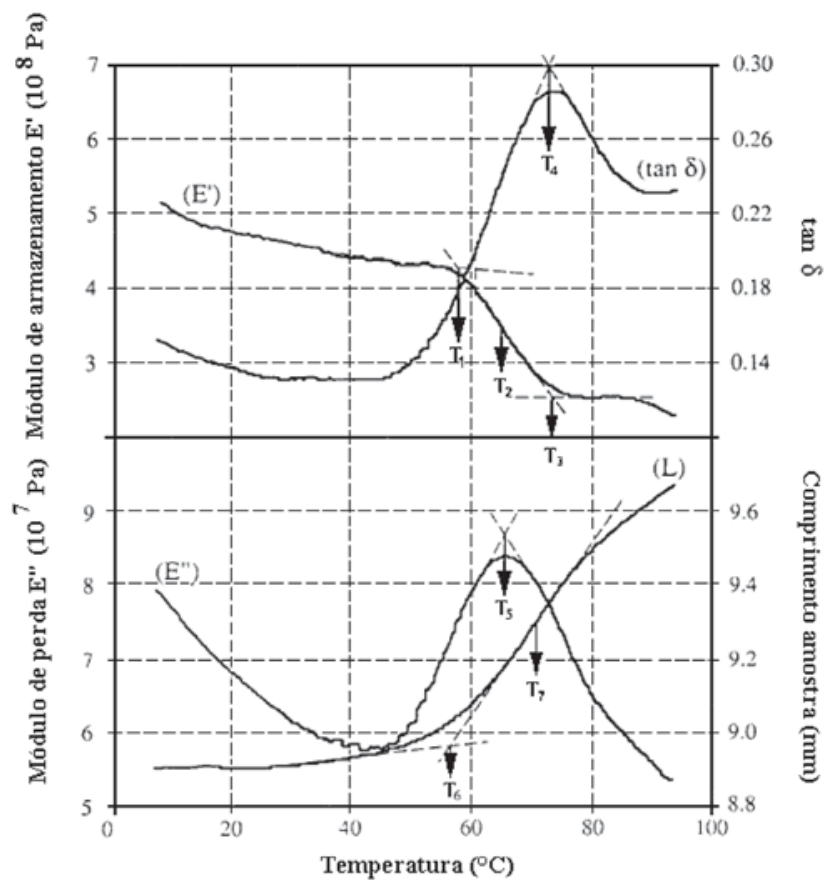

Figura 3. Curvas obtidas na análise dinâmico-mecânica (DMA) com varredura de temperatura, indicando as diferentes maneiras de se determinar o valor da Tg. Adaptada da ref. 42

Teoricamente, considera-se que em um polímero amorfo, a temperatura onde ocorre o pico na curva de $\tan \delta$ está associada ao fenômeno da $\alpha$-relaxação, normalmente visível em testes de varredura de temperatura em DMA (Figura 4), e que corresponde efetivamente à transição vítrea. No resfriamento da amostra, isto é, na transição do estado borrachento para o estado vítreo, o movimento de contorção das cadeias longas é reduzido drasticamente, ficando

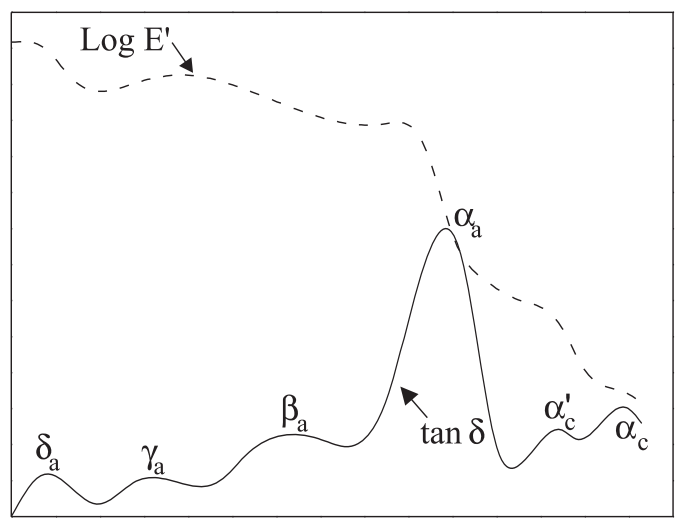

Temperatura $\left({ }^{\circ} \mathrm{C}\right)$

Figura 4. Representação gráfica do comportamento térmico dinâmicomecânico com as curvas de E' e tan $\delta$, incluindo-se as relaxações primárias $\left(\alpha_{c}, \alpha_{c}{ }^{\prime}\right)$ e secundárias $\left(\alpha_{a^{\prime}}, \beta_{a}, \gamma_{a^{\prime}}, \delta_{a}\right)$. Adaptada da ref. 21

as cadeias poliméricas fechadas numa estrutura com capacidade limitada de reorganização.

Comparando-se as curvas de DMA (Figura 5) com as curvas de DSC (Figura 6), de filmes à base de gelatina de peixe (Gel1= gelatina de Fletan, Gel2= gelatina de Atum) plastificados com glicerol, pode-se observar que, efetivamente, a temperatura de transição vítrea, calculada como a inflexão na curva de DSC, é muito similar à temperatura onde ocorre o primeiro pico em $\tan \delta$, em torno de 65 ${ }^{\circ} \mathrm{C}$. Essa similaridade também foi observada por outros autores $^{40,42,58,60,71}$. Entretanto, é possível que essa similaridade não seja observada, uma vez que ambas as técnicas são sensíveis a diferentes graus de mobilidade molecular, sendo a $T_{g}$ medida por DMA dependente da frequiência e a $\mathrm{T}_{\mathrm{g}}$ determinada por DSC dependente da taxa de aquecimento utilizada ${ }^{40}$.

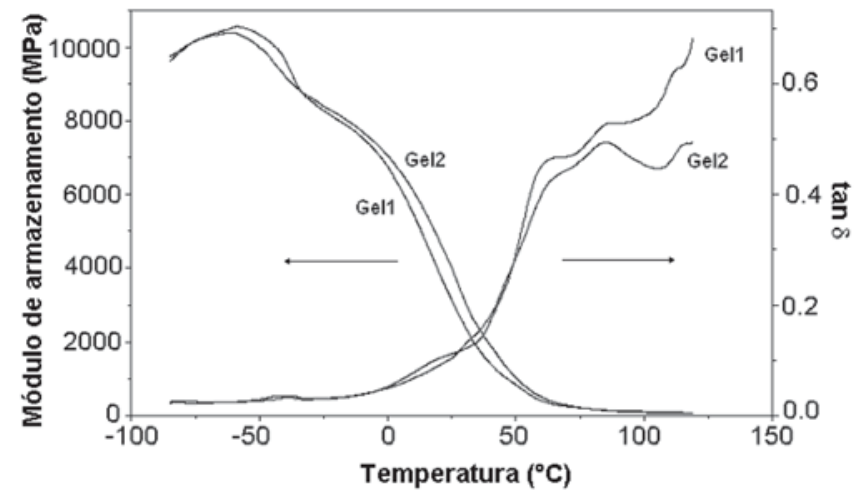

Figura 5. Curvas de módulo de armazenamento e tan $\delta$ de filmes à base de gelatina de peixe (Gel1 e Gel2) utilizando DMA. Reproduzida da ref. 72, com permissão do Instituto Politécnico Nacional

Normalmente, os especialistas em tecnologia de filmes comestíveis estão interessados no efeito da composição da matéria seca do filme e, principalmente, na concentração do(s) plastificante(s), incluindo-se o efeito da umidade do material, sobre a transição vítrea dos respectivos filmes (Tabela 1). Na Figura 7 são apresentadas curvas de $\log E^{\prime}$ e tan $\delta$ para filmes comestíveis feitos com blendas de amido, quitosano e sorbitol a diferentes teores de umidade $^{73}$, nas quais pode-se notar que o aumento da umidade dos filmes provocou um deslocamento da $\mathrm{T}_{\mathrm{g}}$ para valores menores. $\mathrm{O}$ efeito do teor de água sobre o valor da $\mathrm{T}_{\mathrm{g}}$ tem sido observado por vários pesquisadores sobre filmes comestî́veis à base de diferentes 
Tabela 1. Determinação de propriedades termomecânicas de filmes comestíveis no modo varredura de temperatura utilizando DMA

\begin{tabular}{|c|c|c|c|c|c|c|c|}
\hline \multirow[b]{2}{*}{ Biopolímeros } & \multirow[b]{2}{*}{ Plastificantes } & \multirow[b]{2}{*}{ Equipamento } & \multicolumn{4}{|c|}{ Condições de operação } & \multirow[b]{2}{*}{ Ref. } \\
\hline & & & $\begin{array}{c}\text { Modo } \\
\text { do ensaio }\end{array}$ & $\begin{array}{l}\text { Freqüuência } \\
(\mathrm{Hz})\end{array}$ & $\begin{array}{c}\text { Temperatura } \\
\left({ }^{\circ} \mathrm{C}\right)\end{array}$ & $\begin{array}{c}\text { Taxa de } \\
\text { aquecimento } \\
\left({ }^{\circ} \mathrm{C} / \mathrm{min}\right)\end{array}$ & \\
\hline $\begin{array}{l}\text { Amido de arroz, } \\
\text { amido de batata }\end{array}$ & $\begin{array}{l}\text { Frutose, glicose, } \\
\text { sacarose }\end{array}$ & $\begin{array}{l}\text { DMTA MkI, } \\
\text { Polymer Labs. }\end{array}$ & $\begin{array}{l}\text { Simples } \\
\text { cantilever }\end{array}$ & 1 &.-- & 2 & 68 \\
\hline Amido de batata & Glicerol & $\begin{array}{l}\text { DMTA MkIII, } \\
\text { Rheometric Scientific }\end{array}$ & Tração & 1 & $-100-80$ & 3 & 41 \\
\hline Amido de cevada & Glicerol & $\begin{array}{l}\text { DMTA MkII, } \\
\text { Rheometric Sci. }\end{array}$ & Tração & 10 & $-100-60$ & 1 & 43 \\
\hline Amido de feijão & $\begin{array}{l}\text { Sorbitol, glicerol, } \\
\text { glicose, manose, frutose }\end{array}$ & $\begin{array}{l}\text { DMA Q800, } \\
\text { TA Instruments }\end{array}$ & Tração & $1,5,10$ & $-100-80$ & 2 & 55 \\
\hline Amido de mandioca & Glicerol & $\begin{array}{l}\text { DMTA IV, } \\
\text { Rheometric Sci. }\end{array}$ & Tração & 1 & $-90-20$ & 2 & 54 \\
\hline \multirow[t]{2}{*}{ Amido de trigo } & Sorbitol & $\begin{array}{l}\text { DMTA IV, } \\
\text { Rheometric Sci. }\end{array}$ & $\begin{array}{l}\text { Flexão } \\
3 \text { pontos }\end{array}$ & 1 & $-100-100$ & 3 & 62 \\
\hline & & $\begin{array}{l}\text { Mark III, } \\
\text { Rheometric Sci. }\end{array}$ & Tração & 1 & $-80-80$ & 3 & 70 \\
\hline $\begin{array}{l}\text { Amido mandioca } \\
+ \text { Albumina ovo }\end{array}$ & Óleo girassol & $\begin{array}{l}\text { DMA Model 110, } \\
\text { Seiko Instruments }\end{array}$ & $\begin{array}{l}\text { Flexão } \\
3 \text { pontos }\end{array}$ & 1 & $25-130$ & 2.5 & 91 \\
\hline Amilopectina & Sacarose & $\begin{array}{l}\text { Mark III, } \\
\text { Rheometric Sci. }\end{array}$ & Flexão & 1,5 & $-50-50$ & 2 & 44 \\
\hline $\begin{array}{l}\text { Amilose } \\
\text { (de amido de feijão) }\end{array}$ & Glicerol & $\begin{array}{l}\text { MkII, } \\
\text { Rheometric Sci. }\end{array}$ & Tração & 10 & $-100-150$ & 1 & 51 \\
\hline $\begin{array}{l}\text { Amilose, } \\
\text { amilopectina }\end{array}$ & & RSA II, Rheometric Sci. & Tração &.-- & $-80-60$ & 1 & 52 \\
\hline Caseinato de sódio & Glicerol & DMA-7, Perkin Elmer & Tração & 1 & $-30-260$ & 3 & 92 \\
\hline $\begin{array}{l}\text { Caseinato de sódio } \\
+ \text { amido } \\
\text { (milho e trigo) }\end{array}$ & $\begin{array}{l}\text { Sacarose, glicose, } \\
\text { xilose, glicerol }\end{array}$ & $\begin{array}{l}\text { Mark II, } \\
\text { Rheometric Sci. }\end{array}$ & $\begin{array}{l}\text { Simples } \\
\text { cantilever }\end{array}$ & 1 & $-40-160$ & 2 & 58 \\
\hline $\begin{array}{l}\text { Hidroxipropilmetil } \\
\text {-celulose }\end{array}$ & $\begin{array}{l}\text { PEG }(300,600, \\
1500,4000)\end{array}$ & $\begin{array}{l}\text { DMTA, } \\
\text { Polymer Labs. }\end{array}$ & Tração & 1 & $80-200$ & 3 & 53 \\
\hline $\begin{array}{l}\text { Celulose microcris- } \\
\text { talina, } \\
\text { metilcelulose, } \\
\text { amido de milho }\end{array}$ & $\begin{array}{l}\text { Glicerol, sorbitol, } \\
\text { glicose, } \\
\text { sacarose }\end{array}$ & $\begin{array}{l}\text { Mark II, } \\
\text { Polymer Labs. }\end{array}$ & $\begin{array}{l}\text { Simples } \\
\text { cantilever }\end{array}$ & 1 &.-- & 2 & 59 \\
\hline Gelatina & $\begin{array}{l}\text { Ácidos graxos + resina } \\
\text { de "elemi", triacetina }\end{array}$ & DMA TA2980 & Tração & 1 & $-100-150$ & 2 & 86 \\
\hline $\begin{array}{l}\text { Gelatina + amido } \\
\text { solúvel }\end{array}$ & $\begin{array}{l}\text { Glicerol, sorbitol, } \\
\text { sacarose }\end{array}$ & $\begin{array}{l}\text { DMTA Mark II, } \\
\text { Polymer Labs. }\end{array}$ & $\begin{array}{l}\text { Simples } \\
\text { cantilever }\end{array}$ & 1 &.-- & 2 & 69 \\
\hline Glúten de trigo & Glicerol & $\begin{array}{l}\text { DMA } 242 \\
\text { Netzsch Gerätebau }\end{array}$ & $\begin{array}{l}\text { Flexão } \\
2 \text { pontos }\end{array}$ & $\begin{array}{c}1,2.5,5 \\
10,20\end{array}$ & $-150-50$ & 2 & 60 \\
\hline Glúten de trigo & Glicerol & $\begin{array}{l}\text { DMTA Mark I, } \\
\text { Polymer Labs. }\end{array}$ & & 1 & $-20-160$ & 2 & 40 \\
\hline Glúten de trigo & $\begin{array}{l}\text { Sacarose, glicerina, } \\
\text { sorbitol }\end{array}$ & DMA Seiko modelo 110 & $\begin{array}{l}\text { Flexão } \\
3 \text { pontos }\end{array}$ & 1 & $-120-200$ & 2 & 61 \\
\hline $\begin{array}{l}\text { Hidroxipropil amido, } \\
\text { gelatina }\end{array}$ & Glicerol & $\begin{array}{l}\text { DMTA Mark II, } \\
\text { Polymer Labs. }\end{array}$ & $\begin{array}{l}\text { Simples } \\
\text { cantilever }\end{array}$ & 1 &.-- & 2 & 93 \\
\hline Kafirina de sorgo & $\begin{array}{l}\text { Glicerol, PEG 400, } \\
\text { ácido láctico }\end{array}$ & $\begin{array}{l}\text { RSA-II, } \\
\text { Rheometric Sci. }\end{array}$ & Tração &.-- & $-10-60$ & 5 & 94,95 \\
\hline Pectina + amido & Glicerol & RSA II, Rheometric Sci. &.-- &.-- & $-100-200$ &.-- & 57,96 \\
\hline $\begin{array}{l}\text { Pectina + amido } \\
\text { milho }\end{array}$ & Glicerol & RSA II, Rheometric Sci. &.-- & $\begin{array}{c}1.59 \\
(10 \mathrm{rad} / \mathrm{s})\end{array}$ & $25-210$ &.-- & 53,77 \\
\hline $\begin{array}{l}\text { Proteína de músculo } \\
\text { de sardinha }\end{array}$ & Sorbitol + sacarose & DMA-7 Perkin Elmer & Tração & 1 & $-20-200$ & 5 & 42 \\
\hline $\begin{array}{l}\text { Proteína de soja } \\
\text { (isolado) }\end{array}$ & Glicerol & $\begin{array}{l}\text { DMS 210-SII, Seiko } \\
\text { Instruments }\end{array}$ & Tração & 1 & $-100-180$ & 2 & 84 \\
\hline $\begin{array}{l}\text { Proteína soro } \\
\text { de leite }\end{array}$ & Glicerol, sorbitol & $\begin{array}{l}\text { RSA-II, } \\
\text { Rheometric Sci. }\end{array}$ & Tração & 1 & $-65-100$ & 5 & 50 \\
\hline
\end{tabular}


Tabela 1. continuação

\begin{tabular}{|c|c|c|c|c|c|c|c|}
\hline \multirow[b]{2}{*}{ Biopolímeros } & \multirow[b]{2}{*}{ Plastificantes } & \multirow[b]{2}{*}{ Equipamento } & \multicolumn{4}{|c|}{ Condições de operação } & \multirow[b]{2}{*}{ Ref. } \\
\hline & & & $\begin{array}{c}\text { Modo } \\
\text { do ensaio }\end{array}$ & $\begin{array}{l}\text { Freqüência } \\
\qquad(\mathrm{Hz})\end{array}$ & $\begin{array}{l}\text { Temperatura } \\
\left({ }^{\circ} \mathrm{C}\right)\end{array}$ & $\begin{array}{c}\text { Taxa de } \\
\text { aquecimento } \\
\left({ }^{\circ} \mathrm{C} / \mathrm{min}\right)\end{array}$ & \\
\hline $\begin{array}{l}\text { Proteína soro } \\
\text { de leite }\end{array}$ & Sorbitol & $\begin{array}{l}\text { RSA-II, } \\
\text { Rheometric Sci. }\end{array}$ & Tração & 1 & $-60-100$ & 5 & 97 \\
\hline Pululano & Sorbitol & $\begin{array}{l}\text { Mark III, } \\
\text { Polymer Labs. }\end{array}$ & $\begin{array}{l}\text { Simples } \\
\text { cantilever }\end{array}$ & $1,3,10$ & $0-150$ & 2 & 47 \\
\hline Pululano & $\begin{array}{l}\text { Sorbitol, sorbitol + } \\
\text { sacarose }\end{array}$ & $\begin{array}{l}\text { Mark III, Polymer } \\
\text { Labs. }\end{array}$ & $\begin{array}{l}\text { Simples } \\
\text { cantilever }\end{array}$ & $1,3,10$ & $-70-150$ & 2 & 2 \\
\hline $\begin{array}{l}\text { Pululano + amido } \\
\text { de milho }\end{array}$ & Sorbitol, xilose & $\begin{array}{l}\text { Mark III } \\
\text { Polymers Labs. }\end{array}$ & $\begin{array}{l}\text { Simples } \\
\text { cantilever }\end{array}$ & $1,3,10$ & $-60-140$ & 2 & 46 \\
\hline $\begin{array}{l}\text { Pululano + caseinato } \\
\text { de sódio }\end{array}$ & Sorbitol & $\begin{array}{l}\text { Mark III } \\
\text { Polymers Labs. }\end{array}$ & $\begin{array}{l}\text { Simples } \\
\text { cantilever }\end{array}$ & 3 & $-50-110$ & 2 & 48 \\
\hline Quitosano, gelatina & Glicerol & $\begin{array}{l}\text { DMTA Mark II, } \\
\text { Polymer Labs. }\end{array}$ & $\begin{array}{l}\text { Simples } \\
\text { cantilever }\end{array}$ & 1 & $-60-160$ & 2 & 74 \\
\hline $\begin{array}{l}\text { Quitosano, } \\
\text { quitosano + amido, } \\
\text { quitosano + pululano }\end{array}$ & Glicerol & $\begin{array}{l}\text { DMTA Mark II, } \\
\text { Polymer Labs. }\end{array}$ & $\begin{array}{l}\text { Simples } \\
\text { cantilever }\end{array}$ & $1,3,10$ & $-80-100$ & 2 & 73 \\
\hline Quitosano + pectina & Glicerol, ácido lático & RSA II, Rheometric Sci. & & 1.59 & $\begin{array}{l}-100-200 \\
(10 \mathrm{rad} / \mathrm{s})\end{array}$ &.-- & 49 \\
\hline
\end{tabular}

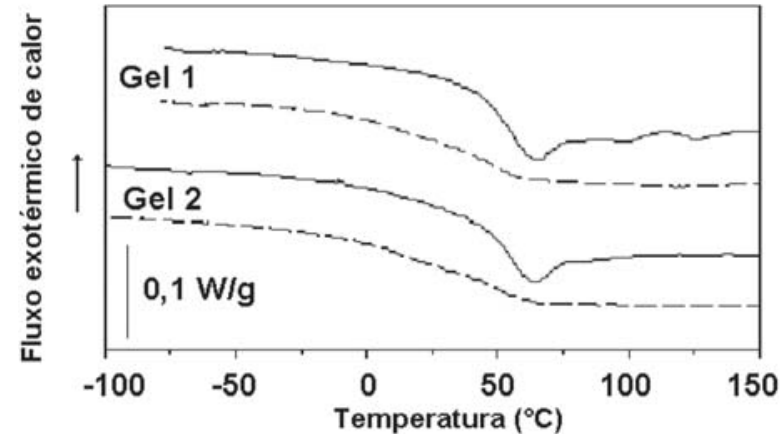

Figura 6. Curvas de DSC de filmes à base de gelatina de peixe (Gell e Gel2). Reproduzida da ref. 72, com permissão do Instituto Politécnico Nacional

macromoléculas, como pululano e caseinato de sódio ${ }^{48}$, pululano ${ }^{2,47}$, quitosano-amido e quitosano-pululano ${ }^{73}$, pululano-amido ${ }^{46}$, quitosano e gelatina ${ }^{74}$, dentre outros, e pode ser explicado pelo efeito plastificante da água, que incrementa o volume livre, diminui a força das interações intermoleculares e incrementa a mobilidade das cadeias poliméricas. Explicações mais detalhadas sobre esse efeito plastificante da umidade podem ser encontradas nos trabalhos de Slade e Levine ${ }^{65}$, Roos e Karel ${ }^{75}$ e Kalichevsky et al. $^{76}$, dentre outros.

Diversos plastificantes estão sendo utilizados na elaboração de filmes e coberturas comestíveis, como indicado na Tabela 1. Entre esses, podem-se destacar mono, di e oligossacarídeos (ex: glicose, frutose, manose, xilose, sacarose), polióis (ex: glicerol, sorbitol, etilenoglicol, di-etilenoglicol, propilenoglicol), lipídios (ex: ácidos graxos saturados, monoglicerídeos, fosfolipídios) e triacetina. $\mathrm{Na}$ determinação das propriedades visco-elásticas dos filmes utilizando DMA, tem-se observado que os valores do módulo de armazenamento (E') diminuem e do pico de $\tan \delta$ aumentam, com o incremento do teor desses componentes ${ }^{55,74,77-79}$, e isso também pode ser explicado pelo efeito que essas moléculas têm sobre a mobilidade das cadeias poliméricas, de maneira similar ao efeito da molécula de água.

A escolha do tipo de plastificante é um processo complexo,

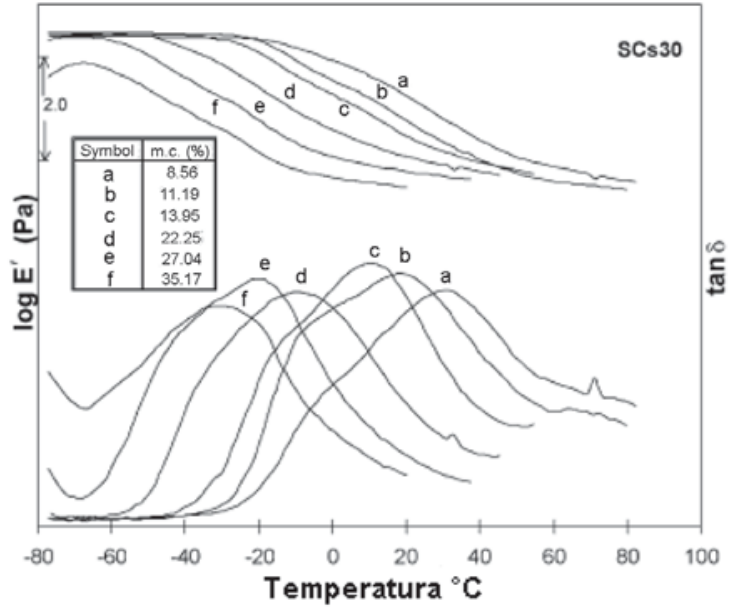

Figura 7. Curvas log E' e tan $\delta$ para filmes à base de blendas de amido/ quitosano/sorbitol (SCs30) com diferentes teores de umidade. Adaptada da ref. 73

pois o mesmo interfere diretamente nas características do filme a ser obtido, já que com o aumento da mobilidade da cadeia polimérica, os coeficientes de difusão também aumentam, resultando em maior permeabilidade aos gases e ao vapor de água ${ }^{80}$. Um efeito importante do uso de plastificantes na produção de filmes é a diminuição da temperatura de transição vítrea $\left(\mathrm{T}_{\mathrm{g}}\right)$ da matriz polimérica, fenômeno muito bem documentado na literatura especializada, como comentado anteriormente.

Além disso, a compatibilidade entre o plastificante e a macromolécula pode ser estudada por DMA. A presença de apenas um pico em $\tan \delta$ significa que o filme forma um sistema físico-químico homogêneo, isto é, que do ponto de vista físico-químico, o biopolímero misturado com o plastificante constitui uma única fase. Entretanto, a observação de um aumento na abertura da base do pico de $\tan \delta$ pode indicar pouca miscibilidade entre o plastificante e o biopolímero, ou mesmo, a presença de micro-heterogeneidades ${ }^{40,46,55,59,73,81}$. A presença de mais de um pico na curva de $\tan \delta$, e em conseqüência mais de uma $\mathrm{T}_{\mathrm{g}}$, pode indicar separação 
de fases ${ }^{43,44,48,53,58,82-86}$. Assim, pode-se considerar que os fenômenos de relaxações $\beta, \gamma, \delta$ ocorrendo a baixas temperaturas (Figura 4), geralmente associados a movimentos locais da cadeia principal do polímero, ou a rotações e vibrações de grupos terminais ou ao movimento de um grupo lateral (movimentos de curta escala) ${ }^{21,67}$, podem na prática, ser associados a fenômenos de separação de fases entre uma fração rica no biopolímero e outra fração rica no plastificante ${ }^{87}$.

Considera-se que esses fenômenos ocorrem em regiões do material onde o movimento é mais fácil, e são chamadas "ilhas de mobilidade" $" 88,89$. A ordem de grandeza dessas transições é muito menor que a $\alpha$-relaxação principal ${ }^{90}$. Esses fenômenos secundários também têm sido observados em filmes comestíveis à base de amido de batata ${ }^{41}$, pululano ${ }^{2,47}$, amilopectina de milho ${ }^{44}$, caseinato de sódio-pululano ${ }^{48}$, quitosana-amido e quitosana-pululano ${ }^{73}$ e quitosana e gelatina ${ }^{74}$. Deve-se salientar que uma quantidade enorme de autores não constatou esses fenômenos, pelo simples fato de terem trabalhado em temperaturas superiores ao domínio onde esses fenômenos ocorrem ${ }^{39,87}$.

Finalmente, deve-se observar que, em termos práticos, a taxa de aquecimento recomendável para os testes de DMA é de $5{ }^{\circ} \mathrm{C} /$ min ou menor, uma vez que utilizar taxas maiores pode criar gradientes térmicos dentro das amostras. Usar uma taxa de $3{ }^{\circ} \mathrm{C} / \mathrm{min}$ é um bom compromisso entre o tempo de duração dos testes e a precisão da temperatura da amostra, uma vez que se minimiza o gradiente térmico nessas. Taxas menores são necessárias para ensaios em baixa freqüência ou multi-freqüência.

\section{Varredura de freqüência}

Para se obter informações sobre as propriedades visco-elásticas de alguns materiais submetidos a relaxamento de tensão, seria necessário acompanhar por um longo tempo a evolução da tensão, o que, na maioria das vezes, inviabilizaria o teste. Freqüientemente, ensaios com duração da ordem de dias, podem não ser ainda suficientes para fornecer o espectro de relaxação de tensões necessário ao estudo de propriedades visco-elásticas do material em questão. Por esta razão, é importante o uso de um método de extrapolação que torne possível determinar as constantes visco-elásticas de um material num ensaio de curta duração ${ }^{19}$.

Em baixas temperaturas, os processos de relaxação de tensão em um polímero ocorrem em tempo muito maior que em temperaturas mais elevadas ${ }^{98}$. As cadeias poliméricas estão imobilizadas em temperaturas muito abaixo da $\mathrm{T}_{\mathrm{g}}$ do material, e as grandes variações de propriedades visco-elásticas, características dos polímeros, não são observadas. Nas proximidades da transição vítrea, as propriedades visco-elásticas dependentes da freqüência e, portanto, do tempo mudam acentuadamente com a temperatura ${ }^{16}$. O aumento da temperatura facilita a mobilidade molecular, fazendo com que o polímero alcance mais rapidamente o equilíbrio em termos de rearranjo molecular ${ }^{99}$.

O comportamento dos polímeros em temperaturas mais baixas pode ser previsto utilizando-se o conceito de superposição tempotemperatura, que permite estabelecer uma relação $\mathrm{a}_{\mathrm{T}}$, denominada fator de transposição, que pode ser calculada pela Equação $8^{100,101}$, na qual $t(T)$ e $t\left(T_{0}\right)$ são tempos e $\omega(T)$ e $\omega\left(T_{0}\right)$ frequiências, a temperaturas diferentes, sendo $\mathrm{T}_{\mathrm{o}}$ a temperatura de referência:

$a_{T}=\frac{t(T)}{t\left(T_{0}\right)}=\frac{\omega\left(T_{0}\right)}{\omega(T)}$

Num polímero amorfo próximo da $\mathrm{T}_{\mathrm{g}}$, todos os processos mecânicos de relaxação ocorrem num tempo curto e muito dependen- te da temperatura.

Para um material visco-elástico submetido a ensaios curtos e isócronos, o efeito da tensão na deformação e a resposta de relaxação a temperaturas mais altas podem ser usados para predizer o efeito isotérmico a longo prazo, da mesma tensão a uma temperatura mais baixa. Tomando-se como referência uma curva obtida numa temperatura desejada, e transportando-se os dados obtidos em outras temperaturas para a temperatura selecionada como referência (mediante transformações horizontais apropriadas do eixo da frequiência ou do tempo) é possível gerar uma curva mestra ("master curve"), que abranja várias ordens de grandeza de tempo, ou grandes variações de frequiência. Essas curvas são muito úteis para se predizer uma grande faixa de efeitos da aplicação de tensões ou deformações sobre propriedades, tais como relaxação de tensões, módulos de armazenamento ou de perda, e $\tan \delta$, dentre outras $^{20,73,98}$.

Além disso, medidas feitas na maioria dos equipamentos comerciais, que operam em uma faixa estreita de freqüência, permitem que o espectro de relaxação possa ser obtido em uma ampla faixa de freqüência, a partir da aplicação do princípio de superposição tempo-temperatura (TTS). Neste caso, faz-se necessária a realização de medidas isotermas, nas quais se realizam varreduras de freqüência, em uma faixa de temperaturas tão ampla quanto possível $^{63}$. Kristo e Biliaderis ${ }^{48}$, por exemplo, geraram uma curva mestra abrangendo uma ampla faixa de frequiências, de $10^{-12}$ a $10^{2} \mathrm{~Hz}$ (14 décadas), a partir de isotermas determinadas entre 55 e $130{ }^{\circ} \mathrm{C}$ e com frequiências de $10^{-1}$ a $10^{2} \mathrm{~Hz}$ (3 décadas), aplicando o principio de superposição tempo-temperatura (Figura 8).

Pode-se notar, na Figura 8a, que os valores do módulo de armazenamento diminuem com a redução das temperaturas dos espectros, o que pode ser explicado pela maior mobilidade das cadeias poliméricas em temperaturas maiores. Segundo Cassu e Felisberti $^{63}$, o efeito da variação da frequiência e da temperatura, sobre o comportamento dinâmico-mecânico de materiais poliméricos pode ser resumido da seguinte forma: a baixas temperaturas ou altas freqüências, o polímero comporta-se como um material vítreo e, portanto, rígido, devido aos altos tempos de relaxação comparativamente à escala de tempo do experimento; nessas condições, o módulo de armazenamento é alto, e o de perda é baixo; a altas temperaturas, ou baixas frequiências, os movimentos internos respondem à tensão aplicada, assim, tanto os módulos de armazenamento, como de perda, são baixos, correspondendo ao comportamento viscoso e, quando a freqüência do experimento é comparável à frequiência dos movimentos internos do material, na temperatura na qual é feita a medida, o módulo de armazenamento diminui com o aumento da temperatura ou com a diminuição da frequiência, e o módulo de perda exibe um máximo, correspondendo ao comportamento visco-elástico.

Nessas condições, a relação entre tempo e temperatura é dada pela Equação de Williams-Landel-Ferry (WLF) (Equação 9):

$\log \mathrm{a}_{\mathrm{T}}=\frac{-\mathrm{C}_{1}\left(\mathrm{~T}-\mathrm{T}_{\mathrm{r}}\right)}{\mathrm{C}_{2}+\left(\mathrm{T}-\mathrm{T}_{\mathrm{r}}\right)}$

na qual: $\log \mathrm{a}_{\mathrm{T}}=$ fator de transposição; $\mathrm{T}=$ Temperatura de medida $(\mathrm{K}) ; \mathrm{T}_{\mathrm{r}}=$ Temperatura de referência $(\mathrm{K}) ; \mathrm{C}_{1}, \mathrm{C}_{2}=$ Constantes relacionadas ao volume livre do material.

A Equação de Williams-Landel-Ferry tem sido utilizada para descrever o comportamento tempo/temperatura em biopolímeros na região de transição vítrea ${ }^{33,102-106}$ e para gerar curvas mestras de filmes comestíveis ${ }^{46-48,73}$. Também tem sido aplicada na predição de mudanças induzidas pela temperatura em farinha de soja ${ }^{107}$, no 
(a)

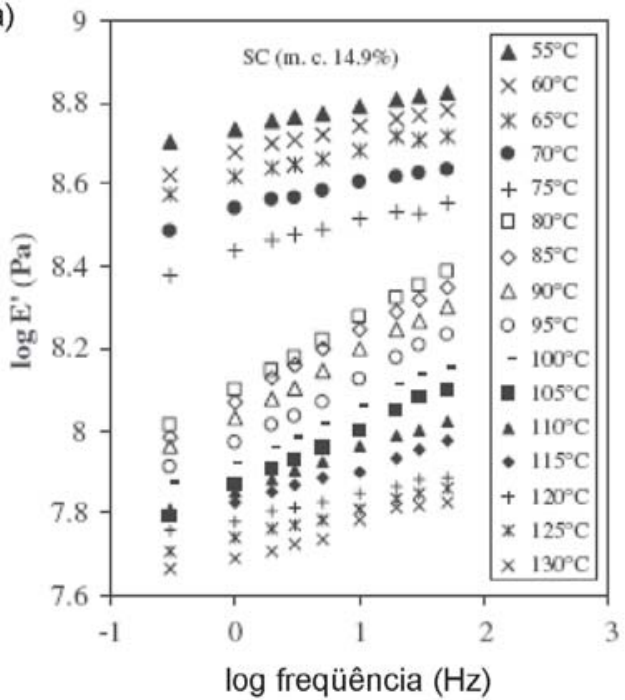

(b)

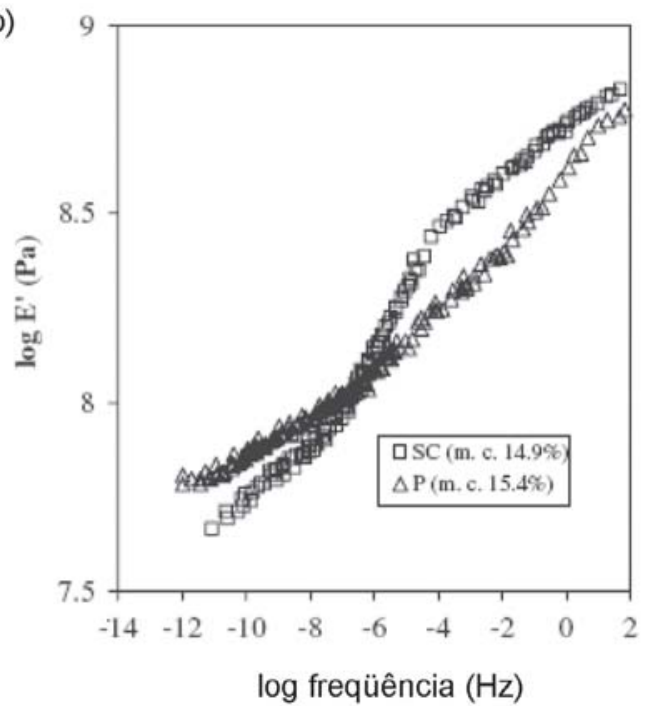

Figura 8. (a) Espectros de DMA de amostras de caseinato de sódio, (b) curvas mestras para filmes de pululano (P) e caseinato de sódio com teores de umidade especificados. Adaptadas da ref. 48

processo de escurecimento não enzimático ${ }^{108-110}$, cinética enzimática $^{111}$, estabilidade de leite em pó ${ }^{112,113}$, modelagem da relação viscosidade-temperatura em mel ${ }^{114}$, estabilidade de soluções congeladas de açúcares ${ }^{115}$, cinética de perda de qualidade ${ }^{116}$, viabilidade de sementes ${ }^{117}$ e crescimento bacteriano ${ }^{118}$. Segundo Peleg ${ }^{119}$, o modelo WLF tem-se mostrado válido, principalmente quando a temperatura de referência $\left(\mathrm{T}_{\mathrm{r}}\right)$, que pode ser arbitrária, é pelo menos $50^{\circ} \mathrm{C}$ acima da temperatura de transição vítrea. Mas o uso de $\mathrm{T}_{\mathrm{g}}$ como temperatura de referência, com os valores das constantes $\mathrm{C}_{1}^{\mathrm{g}}$ e $\mathrm{C}_{2}$ ('constantes universais') iguais a 17,44 (adimensional) e $51,6 \mathrm{~K}$, respectivamente, pode ser inapropriado ${ }^{120}$. Kasapis et al. ${ }^{104}$ e Yildiz e Kokini ${ }^{121}$ indicaram que a variação dos valores de $C_{1}$ e $C_{2}$ é bastante pronunciada para o caso de polímeros alimentícios. No caso de filmes comestíveis, tem-se obtido valores de $\mathrm{C}_{1}$ variando desde 2,86 para blendas de pululano e amido de milho plastificadas com xilose ${ }^{46}$, até 143,57 para quitosana ${ }^{73}$; e valores de $C_{2}$ variando de $12,3 \mathrm{~K}$ para pululano até $626,1 \mathrm{~K}$, em blendas de pululano e caseinato de sódio ${ }^{48}$. Vários trabalhos sobre propriedades termomecânicas de filmes comestíveis, obtidos através de varredura de freqüência, podem ser encontrados na literatura especializada (Tabela 2).

\section{CONSIDERAÇÕES FINAIS}

A análise dinâmico-mecânica tem se constituído em uma metodologia muito útil na determinação do comportamento viscoelástico de filmes comestíveis, permitindo predizer aspectos relacionados com sua estabilidade (tempo) e processabilidade (temperatura).

Em testes de varredura de temperatura, essa técnica permite

Tabela 2. Determinação de propriedades termomecânicas de filmes comestíveis no modo varredura de frequiência utilizando DMA

\begin{tabular}{|c|c|c|c|c|c|c|}
\hline \multirow[b]{2}{*}{ Biopolímeros } & \multirow[b]{2}{*}{ Plastificantes } & \multirow[b]{2}{*}{ Equipamento } & \multicolumn{3}{|c|}{ Condições de operação } & \multirow[b]{2}{*}{ Ref. } \\
\hline & & & $\begin{array}{l}\text { Modo } \\
\text { do ensaio }\end{array}$ & $\begin{array}{l}\text { Freqüência } \\
(\mathrm{Hz})\end{array}$ & $\begin{array}{l}\text { Temperatura } \\
\left({ }^{\circ} \mathrm{C}\right)\end{array}$ & \\
\hline Gelatina &.-- & $\begin{array}{l}\text { DMTA IV, } \\
\text { Rheo-metric Sci. }\end{array}$ & $\begin{array}{l}\text { Simples } \\
\text { cantilever }\end{array}$ & $\begin{array}{l}0.1,0.2,0.5 \\
1,4,10\end{array}$ & 25 & 122 \\
\hline Gelatina & Glicerol, sorbitol & DMA TA2980 & Tração & $0.01-100$ & 30 & 72,123 \\
\hline Pectina &.-- & $\begin{array}{l}\text { DMTA V, } \\
\text { Rheometrics }\end{array}$ & Tração & $\begin{array}{l}1.59 \times 10^{-3}- \\
1.59 \times 10^{2}\end{array}$ &.-- & 124 \\
\hline $\begin{array}{l}\text { Proteína músculo } \\
\text { de tilapia var. Thai }\end{array}$ & Glicerina & DMA TA2980 & Tração & $0.01-200$ & 30 & 79 \\
\hline $\begin{array}{l}\text { Proteína músculo } \\
\text { de tilapia do Nilo }\end{array}$ & Glicerina & DMA TA2980 & Tração & $0.01-200$ & 30 & 78,125 \\
\hline Pululano & Sorbitol & $\begin{array}{l}\text { Mark III, } \\
\text { Polymer Labs. }\end{array}$ & $\begin{array}{l}\text { Simples } \\
\text { cantilever }\end{array}$ & $\begin{array}{l}0.3,1,2,3,5 \\
10,20,30,50\end{array}$ & $55-130$ & 48 \\
\hline Pululano & Sorbitol & $\begin{array}{l}\text { Mark III, } \\
\text { Polymer Labs. }\end{array}$ & $\begin{array}{l}\text { Simples } \\
\text { cantilever }\end{array}$ & $\begin{array}{l}0.3,1,2,3,5 \\
10,20,30,50\end{array}$ & $60-105$ & 47 \\
\hline $\begin{array}{l}\text { Pululano + amido } \\
\text { de milho }\end{array}$ & Sorbitol, xilose & $\begin{array}{l}\text { Mark III } \\
\text { Polymer Labs. }\end{array}$ & $\begin{array}{l}\text { Simples } \\
\text { cantilever }\end{array}$ & $\begin{array}{l}0.3,1,2,3,5 \\
10,20,30,50\end{array}$ & $30-90$ & 46 \\
\hline $\begin{array}{l}\text { Quitosano, } \\
\text { quitosano + amido, } \\
\text { quitosano + pululano }\end{array}$ & Sorbitol & $\begin{array}{l}\text { Mark III } \\
\text { Polymer Labs. }\end{array}$ & $\begin{array}{l}\text { Simples } \\
\text { cantilever }\end{array}$ & $\begin{array}{l}0.3,1,2,3,5 \\
10,20,30,50\end{array}$ & $30-80$ & 73 \\
\hline
\end{tabular}


determinar o valor da temperatura de transição vítrea $\left(\mathrm{T}_{\mathrm{g}}\right)$ desses materiais, que afeta suas propriedades físicas e funcionais. É possível, ainda, estudar separação de fases entre biopolímeros e/ou entre biopolímero/plastificante.

Além disso, realizando-se ensaios em função do tempo, ou da frequiência, pode-se gerar curvas mestras, e, portanto, predizer o comportamento das propriedades dos filmes em tempos muito prolongados.

\section{AGRADECIMENTOS}

Ao CNPq pelo auxílio e bolsa de O. Mendieta - Taboada (PDJ) e de P. J. A. Sobral (PQI), e à FAPESP, pelos auxílios (04/08771-7, 05/57781-8).

\section{REFERÊNCIAS}

1. Kester, J. J.; Fennema, O. R.; Food Technol. 1986, $40,47$.

2. Diab, T.; Biliaderis, C.; Gerasopoulos, D.; Sfakiotakis, E.; J. Sci. Food Agric. 2001, 81, 988.

3. Tharanathan, R. N.; Trends Food Sci. Technol. 2003, 14, 71.

4. Gontard, N.; Guilbert, S.; Bol. Soc. Bras. Ciênc. Tecnol. Aliment. 1996, 30,3 .

5. Nisperos-Carriedo, M. O. Em Edible coatings and films to improve food quality; Krochta, J. M.; Baldwin, E. A.; Nisperos-Carriedo, M., eds.; Technomic Pub. Co. Inc.: Lancaster, 1994, p. 305.

6. Gennadios, A.; McHugh, T. H.; Weller, C. L.; Krochta, J. M. Em ref. 5, p. 210.

7. Torres, J. A. Em Protein functionality in food systems; Hettiarachchy, N. S.; Ziegler, G. R., eds.; Marcel Dekker Inc.: New York, 1994, p. 467.

8. Koelsch, C.; Trends Food Sci. Technol. 1994, 5, 76.

9. Baldwin, E. A.; Nisperos-Carriedo, M. O.; Baker, R. A.; Crit. Rev. Food Sci. Nutr. 1995, 35, 509.

10. Gennadios, A.; Hanna, M. A.; Kurth, L. B.; Lebensm. Wiss. Technol. 1997, $30,337$.

11. Miller, K. S.; Krochta, J. M.; Trends Food Sci. Technol. 1997, 8, 228.

12. Morillon, V.; Debeaufort, F.; Blond, G.; Capelle, M.; Voilley, A.; Crit. Rev. Food Sci. Nutr. 2002, 42, 67.

13. Cagri, A.; Ustunol, Z.; Ryser, E. T.; J. Food Prot. 2004, 67, 833.

14. Debeaufort, F.; Quezada-Gallo, J. A.; Voilley, A.; Crit. Rev. Food Sci. Nutr. 1998, 38, 299.

15. Findley, W. N.; Lai, J. S.; Onaran, K.; Creep and relaxation of nonlinear viscoelastic materials. With an introduction to linear viscoelasticity, Dover Publications Inc.: New York, 1976.

16. Ferry, J. D.; Viscoelastic Properties of Polymers, John Wiley \& Sons: New York, 1980.

17. Midoux, N.; Mécanique et rhéologie des fluides en génie chimique, Ed. Lavoisier: Paris, 1985.

18. Chandra, P. K.; Sobral, P. J. A.; Ciênc. Tecnol. Aliment. 2000, 20, 250.

19. Lázaro, M.; Tese de Doutorado, Universidade de São Paulo, Brasil, 2004.

20. Lucas, E. F.; Soares, B. G.; Monteiro, E. E. C.; Caracterização de Polímeros. Determinação de Peso Molecular e Análise Térmica, E-papers Serviços Editoriais Ltda.: Rio de Janeiro, 2001, cap.11.

21. Canevarolo, S. V. Em Técnicas de caracterização de polímeros; Canevarolo, S. V., ed.; Artliber Ed. Ltda: São Paulo, 2004, p. 263.

22. Solorza-Feria, J.; Jimenez-Aparicio, A.; Arenas-Ocampo, M. L.; BelloPerez, L. A.; Starch/Staerke 2002, 54, 198.

23. Peressini, D.; Bravin, B.; Lapasin, R.; Rizzotti, C.; Sensidoni, A.; J. Food Eng. 2003, 59, 25.

24. Brito, A. C. F.; Sierakowski, M. R.; Reicher, F.; Feitosa, J. P. A.; Paula, R. C. M.; Food Hydrocolloids 2005, 19, 861.

25. Funami, T.; Funami, M.; Yada, H.; Nakao, Y.; Food Hydrocolloids 1999, $13,317$.

26. Rodríguez-Hernández, A. I.; Tecante, A.; Food Hydrocolloids 1999, 13, 59.

27. Won, S. Y.; Choi, W. C.; Lim, H. S.; Cho, K. Y.; Lim, S. T.; Cereal Chem. 2000, 77, 309.

28. Apichartsrangkoon, A.; J. Food Sci. 2002, 67, 653.

29. Gómez-Guillén, M. C.; Turnay, J.; Fernández-Díaz, M. D.; Ulmo, N.; Lizarbe, M. A.; Montero, P.; Food Hydrocolloids 2002, 16, 25.

30. Gudmundsson, M.; J. Food Sci. 2002, 67, 2172.

31. Salazar-Montoya, J. A.; Ramos-Ramírez, E. G.; Delgado-Reyes, V. A.; Carbohydr. Polym. 2002, 49, 387.

32. Simon, A.; Grohens, Y.; Vandanjon, L.; Bourseau, P.; Balnois, E.; Levesque,
G.; Macromol. Symp. 2003, 203, 331.

33. Nickerson, M. T.; Paulson, A. T.; Speers, R. A.; Food Hydrocolloids 2004, $18,783$.

34. Cho, S. M.; Gu, Y. S.; Kim, S. B.; Food Hydrocolloids 2005, 19, 221.

35. Norziah, M. H.; Foo, S. L.; Karim, A. Abd.; Food Hydrocolloids 2006, 20, 204.

36. http://www.triton-technology.co.uk, acessada em Junho 2006.

37. Sobral, P. J. A.; Habitante, A. M. Q. B.; Food Hydrocolloids 2001, 15, 377.

38. Sobral, P. J. A.; Menegalli, F. C.; Bol. Soc. Bras. Ciênc. Tecnol. Aliment. 2002, 36, 35.

39. Sobral, P. J. A, Monterrey-Quintero, E. S.; Habitante, A. M. Q. B.; J. Therm. Anal. Calorim. 2002, 67, 499.

40. Gontard, N.; Ring, S.; J. Agric. Food Chem. 1996, 44, 3474.

41. Lourdin, D.; Bizot, H.; Colonna, P.; J. Appl. Polym. Sci. 1997, 63, 1047.

42. Cuq, B.; Gontard, N.; Guilbert, S.; Polymer 1997, 38, 2399.

43. Forssell, P. M.; Mikkilä, J. M.; Moates, G. K.; Parker, R.; Carbohydr. Polym. 1997, 34, 275.

44. Farhat, I. A.; Mousia, Z.; Mitchell, J. R.; Carbohydr. Polym. 2003, 52, 29.

45. Craig, D. Q. M.; Johnson, F. A.; Thermochim. Acta 1995, 248, 97.

46. Biliaderis, C. G.; Lazaridou, A.; Arvanitoyannis, I.; Carbohydr. Polym. 1999, 40, 29.

47. Lazaridou, A.; Biliaderis, C. G.; Kontogiorgos, V.; Carbohydr. Polym. 2003, $52,151$.

48. Kristo, E.; Biliaderis, C. G.; Food Hydrocolloids 2006, $20,1057$.

49. Hoagland, P. D.; Parris, N.; J. Agric. Food Chem. 1996, 44, 1915.

50. Anker, M.; Stading, M.; Hermansson, A. M.; J. Agric. Food Chem. 2001, 49, 989.

51. Moates, G. K.; Noel, T. R.; Parker, R.; Ring, S. G.; Carbohydr. Polym. 2001, 44, 247.

52. Stading, M.; Rindlav-Westling, A.; Gatenholm, P.; Carbohydr. Polym. 2001, 45, 209.

53. Honary, S.; Orafai, H.; Drug Dev. Ind. Pharm. 2002, $28,711$.

54. Famá, L.; Flores, S. K.; Gerschenson, L.; Goyanes, S.; Carbohydr. Polym. 2006, 66, 8 .

55. Zhang, Y.; Han, J. H.; J. Food Sci. 2006, 71, 109.

56. Coffin, D. R.; Fishman, M. L.; J. Agric. Food Chem. 1993, 41, 1192.

57. Fishman, M. L.; Coffin, D. R.; Onwulata, C. I.; Konstance, R. P.; Carbohydr. Polym. 2004, 57, 401.

58. Arvanitoyannis, I.; Psomiadou, E.; Nakayama, A.; Carbohydr. Polym. 1996, $31,179$.

59. Psomiadou, E.; Arvanitoyannis, I.; Yamamoto, N.; Carbohydr. Polym. 1996, $31,193$.

60. Hochstetter, A.; Talja, R. A.; Helén, H. J.; Hyvönen, L.; Jouppila, K.; Lebensm. Wiss. Technol. 2006, 39, 893.

61. Cherian, G.; Gennadios, A.; Weller, C.; Chinachoti, P.; Cereal Chem. 1995, $72,1$.

62. Gaudin, S.; Lourdin, D.; Forssell, P. M.; Colonna, P.; Carbohydr. Polym. 2000, 43, 33.

63. Cassu, S. N.; Felisberti, M. I.; Quim. Nova 2005, 28, 255.

64. Rindlav-Westling, A.; Stading, M.; Hermansson, A. M.; Gatenholm, P.; Carbohydr. Polym. 1998, 36, 217.

65. Slade, L.; Levine, H.; Crit. Rev. Food Sci. Nutr. 1991, 30, 115.

66. Roos, Y. H.; Phase Transitions in Foods, Academic Press Inc.: California, 1995.

67. Champion, D.; Le Meste, M.; Simatos, D.; Trends Food Sci. Technol. 2000, 11,41 .

68. Arvanitoyannis, I.; Kalichevsky, M.; Blanshard, J. M. V.; Psomiadou, E.; Carbohydr. Polym. 1994, 24, 1.

69. Arvanitoyannis, I.; Psomiadou, E.; Nakayama, A.; Aiba, S.; Yamamoto, N.; Food Chem. 1997, 60, 593.

70. Gaudin, S.; Lourdin, D.; Le Botlan, D.; Ilari, J. L.; Colonna, P.; J. Cereal Sci. 1999, 29, 273.

71. Jagannath, J. H.; Radhica, M.; Nanjappa, C.; Murali, H. S.; Bawa, A. S.; J. Appl. Polym. Sci. 2006, 101, 3948.

72. Thomazine, M.; Carvalho, R. A.; Habitante, A. M.; Sobral, P. J. A.; Montero, P.; Gómez-Guillén, C. Em Libro de artículos en extenso del V Congreso Iberoamericano de Ingeniería de Alimentos; Chanona, J.; Ordorica, C.; Mulet, A.; Alamilla, L.; Sosa, M. E.; Parada, E.; Welty, J.; Gutiérrez, G., eds.; Instituto Politécnico Nacional: México, 2006.

73. Lazaridou, A.; Biliaderis, C.G.; Carbohydr. Polym. 2002, 48, 179.

74. Arvanitoyannis, I.; Nakayama, A.; Aiba, S.; Carbohydr. Polym. 1998, 37, 371.

75. Roos, Y.; Karel, M.; J. Food Sci. 1991, 56, 1676.

76. Kalichevsky, M. T.; Jaroszkiewicz, E. M.; Blanshard, J. M. V.; Int. J. Biol. Macromol. 1992, 14, 257.

77. Fishman, M. L.; Coffin, D. R.; Unruh, J. J.; Ly, T.; J.M.S.-Pure Appl. Chem. 
1996, 33, 639 .

78. Paschoalik, T. M.; García, F. T.; Sobral, P. J. A.; Habitante, A. M. Q. B.; Food Hydrocolloids 2003, 17, 419.

79. Sobral, P. J. A.; Santos, J. S.; García, F. T.; J. Food Eng. 2005, 70, 93.

80. Fairley, P.; Monahan, F. J.; German, J. B.; Krochta, J. M.; J. Agric. Food Chem. 1996, 44, 438.

81. Pouplin, M.; Redl, A.; Gontard, N; J Agric. Food Chem 1999, 47, 538.

82. Kalichevsky, M. T.; Blanshard, J. M. V.; Carbohydr. Polym. 1992, 19, 271.

83. Kalichevsky, M. T.; Jaroszkiewicz, E. M.; Blanshard, J. M. V.; Polymer 1993, 34, 346.

84. Ogale, A. A.; Cunnigham, P.; Dawson, P. L.; Acton, J. C.; J. Food Sci. 2000, 65, 672 .

85. Pommet, M.; Redl, A.; Morel, M. H.; Guilbert, S.; Polymer 2003, 44, 115.

86. Bertan, L. C.; Tanada-Palmu, P. S.; Siani, A. C.; Grosso, C. R. F.; Food Hydrocolloids 2005, 19, 73

87. Sobral, P. J. A.; Menegalli, F. C.; Hubinger, M. D.; Roques, M. A.;. Food Hydrocolloids 2001, 15, 423.

88. Simatos, D.; Blond, G.; Perez, J. Em Food Preservation by Moisture Control; Barbosa-Cánovas, G.V.; Welti-Chanes, J., eds.; Technomic Publishing: Lancaster, 1995, p. 3.

89. Montés, H.; Mazeau, K.; Cavaillé, J. Y.; Macromolecules 1997, 30, 6977.

90. Sperling, L. H.; Introduction to physical polymer science, WileyInterscience: New York, 1986.

91. Wongsasulak, S.; Yoovidhya, T.; Bhumiratana, S.; Hongsprabhas, P.; McClements, D. J.; Weiss, J.; Food Res. Int. 2006, 39, 277.

92. Khwaldia, K.; Banon, S.; Perez, C.; Desobry, S.; J. Dairy Sci. 2004, 87, 2011.

93. Arvanitoyannis, I.; Nakayama, A.; Aiba, S.; Carbohydr. Polym. 1998, 36, 105.

94. Emmanbux, M. N.; Stading, M.; Taylor, J. R. N.; J. Cereal Sci. 2004, 40, 127.

95. Emmanbux, M. N.; Stading, M.; Taylor, J. R. N.; Annu. T. Nord. Rheol. Soc. 2004, 12, 251

96. Fishman, M. L.; Coffin, D.R.; Konstance, R. P.; Onwulata, C .I.; Carbohydr Polym. 2000, 41, 317.

97. Anker, M.; Stading, M.; Hermansson, A. M.; J. Agric. Food Chem. 1999 47,1878

98. Vaidyanathan, T. K.; Vaidyanathan, J.; Cherian, Z.; Dent. Mater. 2003, 19 , 46

99. Billmayer, F. W.; Textbook of polymers science, $3^{\text {rd }}$ ed., John Wiley \& Sons:
New York, 1984, cap.11.

100. Kao, N.; Bhattacharya, S. N.; Shanks, R.; Coopes, I. H.; J. Rheol. 1998 $42,493$.

101. Yoo, B.; J. Food Eng. 2004, 65, 459.

102. Kasapis, S.; J. Agric. Food Chem. 2004, 52, 2262.

103. Kasapis, S.; Sablani, S. S.; Biliaderis, C. G.; Carbohydr. Res. 2000, 329 179.

104. Kasapis, S.; Al-Alawi, A.; Guizani, N.; Khan, A. J.; Mitchell, J. R.; Carbohydr. Res. 2000, 329, 399.

105. Papageorgiu, M.; Kasapis, S.; Richardson, R. K.; Carbohydr. Polym. 1994, $25,101$.

106. Sworm, G.; Kasapis, S.; Carbohydr. Res. 1998, 309, 353

107. Ashokan, B.; Kokini, J. L.; Rheol. Acta 2005, 45, 192.

108. Miao, S.; Roos, Y. H.; J. Agric. Food Chem. 2004, 52, 5250.

109. Lievonen, S. M.; Laaksonen, T. J.; Roos, Y. H.; J. Agric. Food Chem. 2002, $50,7034$.

110. Sá, M. M.; Sereno, A. M.; Int. J. Food Sci. Technol. 1999, 34, 343.

111. Terefe, N. S.; van Loey, A.; Hendrickx, M.; Innov. Food Sci. Emerg. Technol. 2004, 5, 335 .

112. Roos, Y. H.; Le Lait 2002, 82, 475.

113. Vuataz, G.; Le Lait 2002, 82, 485.

114. Sopade, P. A.; Halley, P.; Bhandari, B.; D'Arcy, B.; Doebler, C.; Caffin, N.; J. Food Eng. 2002, 56, 67.

115. Cruz, I. B.; Oliveira, J. C.; MacInnes, W. M.; Int. J. Food Sci. Technol. 2001, $36,539$.

116. Tsimidou, M.; Biliaderis, C. G.; J. Agric. Food Chem. 1997, 45, 2890.

117. Sun, W. Q.; Ann. Bot. 1997, 79, 291.

118. Schaffner, D. W.; Int. J. Food Microbiol. 1995, 27, 107.

119. Peleg, M.; Crit. Rev. Food Sci. Nutr. 1992, 32, 59.

120. Collares, F. P.; Kieckbusch, T. G.; Finzer, J. R. D.; Braz. J. Food Technol. $2002,5,117$.

121. Yildiz, M. E.; Kokini, J. L.; J. Rheol. 2001, 45, 903.

122. Badii, F.; Martinet, C.; Mitchell, J. R.; Farhat, I. A.; Food Hydrocolloids 2006, 20, 879 .

123. Thomazine, M.; Carvalho, R. A.; Sobral, P. J. A.; J. Food Sci. 2005, 70, 172.

124. Giancone, T.; Di Pierro, P.; Mariniello, L.; Porta, R.; Masi, P.; Chem. Eng. Trans. 2005, 6, 965

125. Sobral, P. J. A.; García, F. T.; Habitante, A. M. Q. B.; Monterrey-Quintero, E. S.; Pesq. Agropec. Bras. 2004, 39, 255. 